\title{
補強用ポリエチレンテレフタレート繊維表面の分子構造に関する研究
}

\author{
広島大学産学連携センター 正路大輔 \\ 広島県立西部工業技術センター 伊藤幸一 \\ 広島大学大学院工学研究科 高田忠彦
}

\section{Study on Molecular Structure in the Surface of Polyethylene Terephthalate Fiber for the Industrial Use}

\author{
Daisuke Shouro $^{* 1}$, Koichi Ito ${ }^{* 2}$, and Tadahiko Takata ${ }^{* 3}$ \\ ${ }^{* 1}$ Hiroshima University Collaborative Research Center, 2-313, Kagamiyama, Higashi-Hiroshima, \\ Hiroshima 739-8528, Japan \\ ${ }^{* 2}$ Hiroshima Prefecture Industrial Research Institute Western, 2-10-1, Aga-Minami, Kure, \\ Hiroshima 737-0004, Japan \\ ${ }^{*}$ Graduate School of Engineering, Hiroshima University, 2-313, Kagamiyama, Higashi-Hiroshima, \\ Hiroshima 739-8528, Japan
}

\begin{abstract}
The surfaces on the two types of polyethylene terephthalate (PET) fibers, R (Regular grade) fiber and HL (High modulus and low shrinkage) fiber with good dimensional stability for the industrial use were analyzed by contact angle, surface tension and X-ray Photoelectron Spectroscopy (XPS). The surface tension of hydrogen bond contributions $\gamma_{S}^{h}$ of all PET samples was very small value, therefore, these samples were very inactive for the chemical interaction. Regarding surface tension of PET film, the polarity $\gamma_{s}^{p}$ was very small, but the dispersion $\gamma_{s}^{d}$ was major contribution. On the other hand, the polarity $\gamma_{S}^{p}$ of the PET fibers showed very large value, but their dispersion $\gamma_{S}^{d}$ was small. These values were different from those of the PET film. It was estimated that the surfaces of PET R-fiber and HL-fiber might be covered with specific chemical structures with polarity such as ethylene glycol chain or ester bond, respectively different from that of ordinary PET film from the analysis of XPS.
\end{abstract}

(Received 5 November, 2004; Accepted 15 February, 2005)

\section{1. 緒 言}

タイヤ, 伝動ベルト及びホースなどゴム複合材に利用さ れる補強瀻維は, 高強度, 高寸法安定性など, 優れた力学 的な性能とゴムに対する高接着性が要求される. ポリエス テル（ポリエチレンテレフタレート：PET）緎維は, 代表 的なゴム補強用繊維として知られ, 優れた力学的な性能を 有するが，その表面は官能基が少なく，ゴム用接着剤とし て汎用的に使用されているレゾルシン・ホルマリン・ゴム ラテックス（RFL）との反応性に乏しいためゴムとの接着 性が低く, 実用上大きな課題となっていた. この課題を解 決するために, 化学処理及び物理処理など多くの表面処理 技術が開発され，既に，実用的な接着レベルが得られてい る[1]. ゴム補強用 PET 瀻維は, regular (R)繊維と, 寸法安 定性に優れた高弾性/低収縮 (High modulus and low shrinkage：HL) 繊維[2]など, 種々開発されている。これら の PET 繊維の物性や微細構造は, 重合度, 製糸条件により
変化することが知られている [3-13] 。しかし, 接着に関 与する表面構造に関しては, R-瀻維，HL-緘維共に殆ど知 見がなく, 表面不活性であるポリエステルフィルムの表面 と同等であると推定されてきた.

しかし, 更なる接着レベルの向上（例えば，耐熱接着技 術：高温加硫時での PET 繊維劣化による接着性低下）を期 待するには, 補強用 PET 繊維の表面構造を明らかにする必 要がある.

本報告においては, PET 繊維の表面の物理化学構造につ き $\mathrm{R}$ 繊維及び寸法安定性に優れた $\mathrm{HL}$ 瀻維について, PET フィルムを比較に入れ, 接触角 (濡れ性), 表面張力, $\mathrm{X}$ 線光電子分光法 (XPS) 測定結果から解析し, その違いを 明らかにすることを試みた。

\section{1 供試料}

\section{2. 実験}

PET2 軸延伸フィルム及び 2 種の PET 繊維はすべて帝人 
テクノプロダクツ株式会社から提供を受けた. これらの繊 維は，いずれも直延伸法 (spin-draw process)によって製造 された $1100 \mathrm{dtex} / 250$ フィラメントのタイヤコード用原糸 である. 寸法安定性 DS は R-瀻維が 9.5\%, HL-纎維が $7.2 \%$ である.

すべての PET 供試料は, アセトンハメタール 50/50 $\mathrm{Vol} . \%$ 溶液で 10 分間 $\times 3$ 回, 超音波洗浄し, 表面付着物(繊

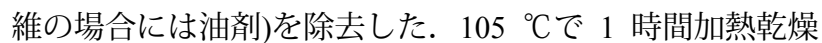
させたのち，測定前までシリカゲル入りデシケータ中に $25{ }^{\circ} \mathrm{C}$ で 24 時間以上静置し, 測定に供した.

\section{2 物性評価}

供試料の物性は以下に述べる方法により測定され， Table 1 に示すデータを得た. ただし, Table 1 の物性はバ ルクの物性であり, 供試料の表面物性ではない.

1) 各 PET サンプルの結晶化度 $(X c)$, 結晶中の分子配向 度 $(F c)$ はX線回折法から求めた。

2 ) カルボキシル $(\mathrm{COOH})$ 基数は各 PET サンプルをベン ジルアルコールに溶解し, これにクロロホルムを加え, フ エノールレッドを指示薬として $\mathrm{N} / 10$ 規定の水酸化ナトリ ウム・ベンジルアルコール溶液により中和滴定することに より求めた。

3) 固有粘度 $[\eta]$ は PET サンプルをクロロフェノールに 溶解し, 濃度の異なる 3 種類の溶液を調整し, ウベローデ 粘度管を使用して溶液落下時間を測定し, それぞれの濃度 の比粘度を計算により求めることにより決定した。

4 ）分子の配向をあらわす複屈折率 $\Delta n$ は偏光顕微鏡を 用いてコンペンセータ法により求めた.

5) 寸法安定性 DS は $2.25 \mathrm{~kg}$ 荷重伸度（日本工業規格 化学繊維タイヤコード試験法 L-1071 に準じて測定）と $150{ }^{\circ} \mathrm{C} \times 30$ 分間熱処理時のフリー収縮率を合計して求め た.

Table 1 Properties of the PET films and fibers: $D S$ dimension stability, $[\eta]$ intrinsic viscosity, $\Delta n$ birefringence, $X c$ crystallinity, $F c$ molecular orientation in crystal region.

\begin{tabular}{ccccc}
\hline & $\begin{array}{c}D S \\
1 \%\end{array}$ & $\begin{array}{c}\text { Thickness, } \\
\text { diameter } / \mu \mathrm{m}\end{array}$ & $\begin{array}{c}\mathrm{COOH} \\
/ 10^{-6} \mathrm{eq} \mathrm{g}^{-1}\end{array}$ \\
\hline Drawn film & - & \multicolumn{2}{c}{125} & 39.5 \\
R-fiber & 9.5 & 20 & 35.0 \\
HL-fiber & 7.2 & \multicolumn{2}{c}{20} & 18.0 \\
\hline \hline & {$[\eta]$} & $\Delta \mathrm{n}$ & $X c$ & $F c$ \\
\hline Drawn film & 0.58 & - & 67.6 & 70.6 \\
R-fiber & 0.88 & 0.199 & 49.0 & 94.0 \\
HL-fiber & 0.91 & 0.183 & 45.0 & 94.0 \\
\hline
\end{tabular}

\section{3 接触角測定と固体表面張力の算出}

各種液体と PET サンプルの濡れ性を評価するために, 接 触角を液滴形状測定により行った。 測定機器は FACE CA-XP（協和界面化学製）を用いた。測定䨌囲気は気温 $25{ }^{\circ} \mathrm{C}$ ・湿度 $50 \%$ 以下であり, 液滴形状からの接触角決定 は日/2 法で行った。

用いた液体はイオン交換水，ホルムアミド，ジョードメ タン, n-へキサデカンである.これらの液体は table 2 に示 したように表面張力 $\gamma_{L}$ とその成分（分散力 $\gamma_{L}{ }^{d}$, 極性力 $\gamma_{L}{ }^{p}$, 水素結合力 $\left.\gamma_{L}{ }^{h}\right)$ が既知であるから, 拡張 Fowkes 式(1)を解 くことにより, 固体である PET サンプルの表面張力 $\gamma_{S}$ とそ の成分 (分散力 $\gamma_{s}^{d}$, 極性力 $\gamma_{s}^{p}$, 水素結合力 $\gamma_{s}^{h}$ ) 求めた[14].

$$
\begin{gathered}
\gamma_{L}(1+\cos \theta)=2\left(\gamma_{S}^{d} \cdot \gamma_{L}^{d}\right)^{1 / 2}+2\left(\gamma_{S}^{p} \cdot \gamma_{L}^{p}\right)^{1 / 2}+2\left(\gamma_{S}^{h} \cdot \gamma_{L}^{h}\right)^{1 / 2} \\
\gamma_{S}=\gamma_{S}^{d}+\gamma_{S}^{p}+\gamma_{S}^{h}, \quad \gamma_{L}=\gamma_{L}^{d}+\gamma_{L}^{p}+\gamma_{L}^{h}
\end{gathered}
$$

PET 繊維はマルチフィラメントであるため, 接触角は, 単繊維で測定した。測定に際しては, 毛細管現象による接 触角低下 $[15]$ を軽減するために, 液滴の直径を単繊維直径

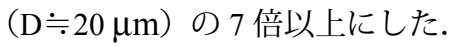

Table 2 Surface tension of Liquids: $\gamma_{L}$ the surface tension of liquid, contributions of $\gamma_{L}^{d}$ dispersive, polar $\gamma_{L}^{p}$, hydrogen-bonded $\gamma_{L}^{h}$ components.[14]

\begin{tabular}{ccccc}
\hline & \multicolumn{4}{c}{ Surface tension $/ \mathrm{mN} \mathrm{m}^{-1}$} \\
\cline { 2 - 5 } & $\gamma_{L}$ & $\gamma_{L}{ }^{1}$ & $\gamma_{L}^{p}$ & $\gamma_{L}^{h}$ \\
\hline Water & 72.8 & 29.1 & 1.3 & 42.4 \\
Formamide & 58.2 & 35.1 & 1.6 & 21.5 \\
Diiodomethane & 50.8 & 46.8 & 4.0 & 0.0 \\
n-Hexadecane & 27.6 & 27.6 & 0.0 & 0.0 \\
\hline
\end{tabular}

\section{4 X 線光電子分光 $(X P S)$ 分析}

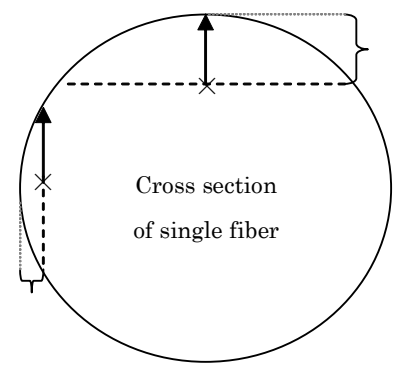

Fig. 1 Cross-section diagram of single fiber showing photoelectrons from different positions.

Fig. 1 に示したように単瀻維には曲率があるため, 表面 に対する X 線入射角は 0 から $90^{\circ}$ まであらゆる角度を取 る. そのため, 平板状のサンプルと比べて深度が浅い光電 子が多く含まれるスペクトルが観測される[16]. また, 脱 出角度の低い光電子が四方に散乱するため通常の検出器 ではよい感度が得にくい，そこで, XPS は ESCALAB 220i-XL (VG Co., Ltd.)で実施した (X 線源は Al Ko). 四方に 
散乱する光電子は Fig. 2 に示した付属の XL-レンズ（磁場 集光を行う検出器）により検出した. XL-レンズの効果に より, 脱出角度の低い光電子を回収できるため, XL-レン ズを用いない場合と比べて cps 值が高感度になった。 用い た $\mathrm{X}$ 線源が $\mathrm{Al}$ Kaであるから, 光電子の最大脱出深度は約 $35 \AA$ と考えられるが，XL-レンズの働きにより低角度で脱 出する光電子を回収するため, 約 35 A 以内の表面近傍を分 析していると推定される.

PET 瀻維の場合, XPS 測定用サンプルは, 導電性カーボ ンテープ上に単瀻維を 1 本ずつ直角に交差させて単繊維を 積み重ねる作業を 30 回行い, テープ上から数百 $\mu \mathrm{m}$ 浮いた 単繊維の集合体を作成した. XL-レンズの磁場集光システ ムの焦点を瀻維集合体上部に合わせると, 繊維下のテープ から出る光電子を回収することが困難になり, 纎維表面の スペクトルが再現性よく高い感度で得られた。

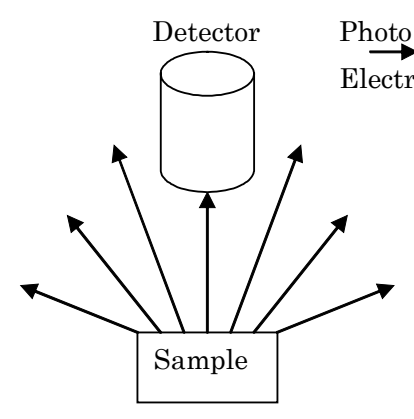

(a) Normal lens

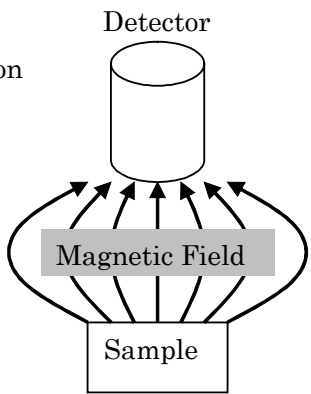

(b) XL lens
Fig. 2 Diagram of Normal lens and XL lens.

\section{3. 結果と考察}

\section{1 表面張力からみた表面特性}

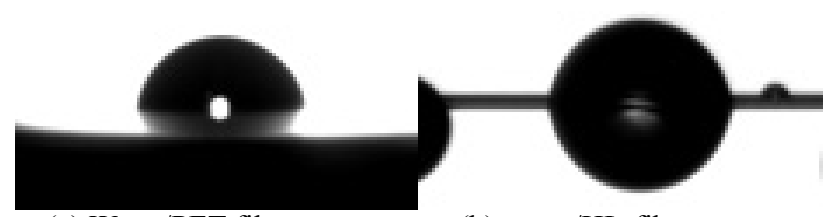

(a) Water/PET film

(b) water/HL-fiber

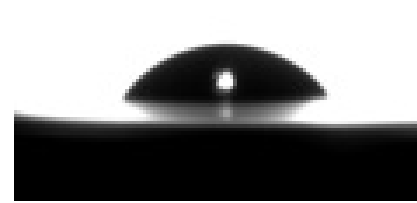

(c) Formamide/PET film

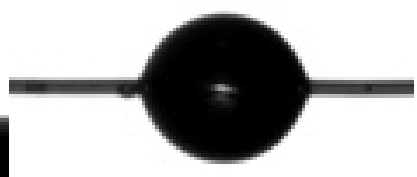

(d) Formamide/HL-fiber

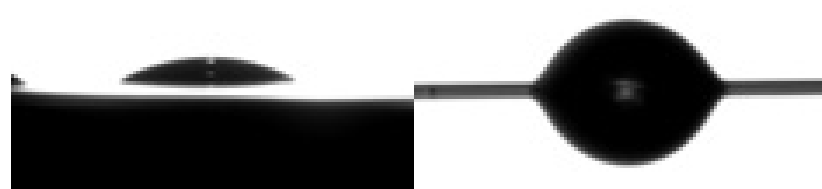

(e) Diiodomethane/PET film (f) Diiodomethane/HL-fiber

Fig. 3 Droplet photographs of liquids on the surface of PET samples.
PET フィルム及び2種の PET 繊維と各種液体との接触角 および表面張力を,それぞれ Table 3 および Table 4 に示す. また, PET フィルム及び HL-瀻維の 3 種の液体種により形 成された液滴を Fig. 3 に示した. 写真から明らかなように PET フィルムと HL-瀻維では同じ液体でも液滴の形状, 即 ち,濡れ性は異なる. 特に, 極性の低い液体の形状の差が著 しく異なる. また, Table 4 からわかるように，いずれのサ ンプルも水素結合力 $\gamma_{s}^{h}$ が非常に小さく, 化学的に不活性で あることが分かる. PET フィルムの表面張力は, 極性力 $\gamma_{s}^{p}$ の寄与が非常に小さく分散力 $\gamma_{s}^{d}$ の寄与が最も大きい.

これらの值は, 報文[14]に扔ける PET フィルムの表面張 力とほぼ同じ值であった.この結果は, 表面が炭化水素の ような構造に覆われており疎水性であることを示す.この 炭化水素は, PET 鎖中のベンゼン環やエチレングリコール 部のエチレン鎖だと推定される.

Table 3 Liquids contact angles on the PET film or fibers.

\begin{tabular}{cccc}
\hline & \multicolumn{3}{c}{ Contact angle $/^{\circ}$} \\
\cline { 2 - 4 } & Drawn film & R-fiber & HL-fiber \\
\hline Water & 77.7 & 76.7 & 77.2 \\
Formamide & 54.7 & 75.6 & 75.6 \\
Diiodomethane & 30.1 & 67.1 & 66.9 \\
n-Hexadecane & 0.0 & 69.2 & 69.3 \\
\hline
\end{tabular}

Table 4 The surface tensions of PET film and PET fibers calculated by expanded Fowkes equations: $\gamma_{S}$ the PET surface tension, contributions of dispersive $\gamma_{S}^{d}$, polar $\gamma_{S}^{p}$, hydrogen-bonded $\gamma_{S}^{h}$ components .

\begin{tabular}{cccccc}
\hline & \multicolumn{5}{c}{ Surface tension $/ \mathrm{mN} \mathrm{m}^{-1}$} \\
\cline { 2 - 6 } & $\gamma_{S}$ & $\gamma_{S}^{d}$ & \multicolumn{1}{c}{$\gamma_{S}^{p}$} & $\gamma_{S}^{h}$ & \\
\hline \multirow{2}{*}{ Drawn film } & 46.0 & 43.0 & 1.6 & 1.3 & WFD* $^{*}$ \\
& 51.4 & 12.7 & 29.9 & 8.8 & WDH $^{*}$ \\
& 45.8 & 12.7 & 29.9 & 3.2 & FDH $^{*}$ \\
R-fiber & 51.6 & 12.6 & 30.5 & 8.5 & WDH $^{*}$ \\
& 46.3 & 12.6 & 30.5 & 3.2 & FDH $^{*}$ \\
\hline
\end{tabular}

*WFD: Water-Formamide-Diiodomethane

*WDH: Water-Diiodomehtane-n-Hexadecane

*FDH: Formamide- Diiodomehtane-n-Hexadecane

PET フィルム表面張力の極性力成分の寄与がほとんど 無い事実は，極性の高い構造が表面に無い，若しくは対称 性を有して配列しているために極性が打ち消されている ことを意味する. PET 鎖中には極性の大きいエステル結合 部が多いため, 極性構造が対称的配列したことにより, 極 性力が打ち消されていることが考えられる.

一方, PET 繊維の表面張力は, 分散力 $\gamma_{S}^{d}$ の寄与が非常に 小さく極性力 $\gamma_{s}^{p}$ の寄与が最も大きい. これらの值は PET 
フィルムの值と全く異なる。この結果から，PET瀻維の表 面は極性力の高い構造で覆われており, かつ極性が打ち消 されてない配列を有していることが示唆される. 極性力が 高くなる条件として双極子モーメントのベクトルが一方 向に揃う必要がある. この条件に合致するのは, 分子鎖に 規則的に存在する部分があるということである. 製糸工程 中の熱履歴や不純物の混入のようなべクトルの向きが揃 え得ないランダム発生的な要因では説明できない. PET 鎖 中に高い極性を持つ構造はエステル結合と末端カルボキ シル基と水酸基である. しかし, その数は, エステル結合 が最も多く, 極性部分はエステル結合と推定される.

\section{2 XPS からみた表面分子構成}

更に, PET フィルム及び PET 繊維について XPS による 測定を行い, XPS スペクトルを得た. $\mathrm{C}_{1 \mathrm{~s}} 285 \mathrm{eV}$ 及び $\mathrm{O}_{1 \mathrm{~s}} 535$ $\mathrm{eV}$ 領域について波形分離操作を行い, それぞれ Fig. 4 及び Fig. 5 を得た. $C_{1 \mathrm{~s}}$ ピークは 285, 287, 289, $293 \mathrm{eV}$ の 4 つ のピークに分割することが出来た．これらのピークはそれ ぞれベンゼン環 $\left(\mathrm{C}_{6} \mathrm{H}_{4}\right)$ の C-C 結合, エチレングリコール鎖 (-O- $\left.\mathrm{CH}_{2}-\mathrm{CH}_{2}-\mathrm{O}-\right)$ )の C-O 結合, エステル結合(-O-CO-)の C $=\mathrm{O}$ 結合及び $\pi \rightarrow \pi$ *シェークアップ（sh）に帰属される.

PET フィルムの XPS $\mathrm{C}_{1 \mathrm{~s}}$ スペクトルはすでに報告[17]さ れている典型的なスペクトルと同様であった。一方， 2 種 の PET 繊維はいずれもこれまでに報告されている PET 織 物スペクトル $[16,18]$ と, 全く異なるXPS スペクトルを示し ている. 重合度, 製糸条件の違いを反映したものと推定さ れるが，以下に詳しく述べる.

Table 5 に PET フィルム, R-繊維及び HL-繊維の各結合 の帰属を面積\%で示す. 即ち, PET フィルムの $\mathrm{C}_{1 \mathrm{~s}}$ 領域は ベンゼン環炭素 $66 \%$, エチレングリコール鎖 $(\mathrm{EG})$ 炭素 $18 \%$ 及びカルボニル炭素 $16 \%$ で構成されていた. R-繊維 の $\mathrm{C}_{1 \mathrm{~s}}$ 領域はべンゼン環炭素 $14 \%$, EG 炭素 $62 \%$ 及びエス テル結合炭素 $24 \%$ で構成されていた. HL-瀻維の $\mathrm{C}_{1 \mathrm{~s}}$ 領域 はベンゼン環炭素 $15 \%$, EG 炭素 $15 \%$ 及びエステル結合炭 素 $70 \%$ で構成されていた， $\mathrm{C}_{1 \mathrm{~s}}$ スペクトルから算出される $\mathrm{O} / \mathrm{C}$ はフィルムが 0.34 と低いのに比べて, R-繊維は 0.86 , HL-瀻維は 0.85 と極めて高い。これらの結果から, PET フ イルム，R-繊維及び HL-瀻維がそれぞれベンゼン環，エチ レングリコール鎖およびエステル結合など特定の構造が 支配的な特徴ある表面を有することがわかった.

Fig. 5 に示す $\mathrm{O}_{1 \mathrm{~s}}$ 領域では, 瀻維 2 種について, フィルム と比べて非常に強いスペクトルが観測された.これらの結 果から PET 瀻維の表面は酸素が豊富であることがわかっ た.この結果は, $\mathrm{C}_{1 \mathrm{~s}}$ スペクトルから算出した両繊維の高 い $\mathrm{O} / \mathrm{C}$ を裏付けている.

以上の結果は, PET フィルムと PET 縉維の表面張力の極 性力成分の違いを裏付けている.
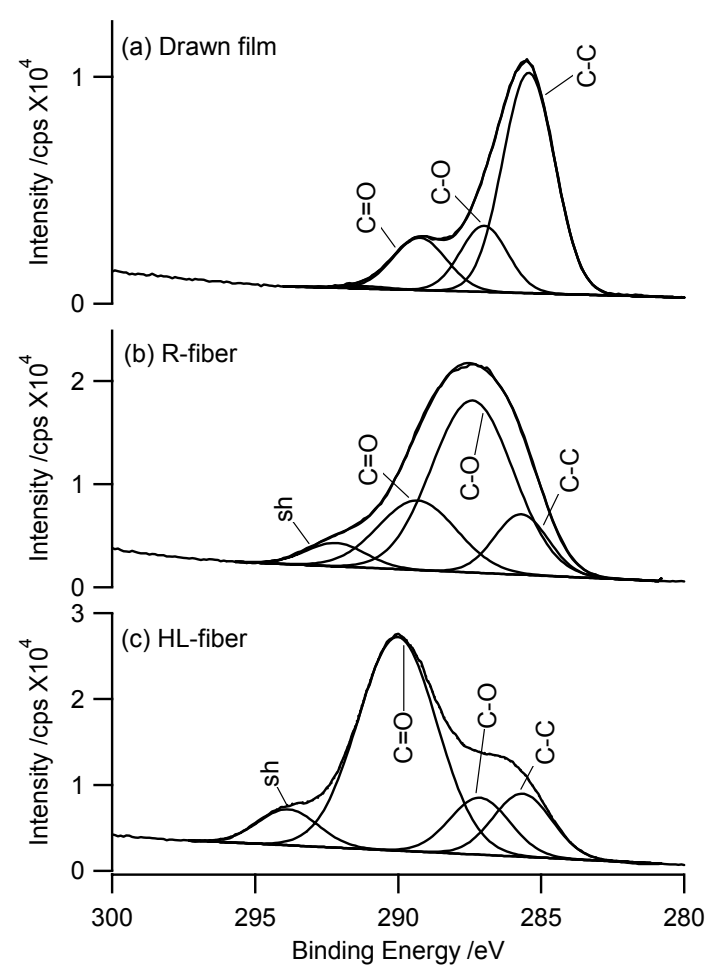

Fig. 4 XPS spectra of the $C_{1 s}$ peak region at $285 \mathrm{eV}$ deconvoluted into surface functional group contributions for (a) drawn film, (b) R-fiber and (c) HL-fiber.
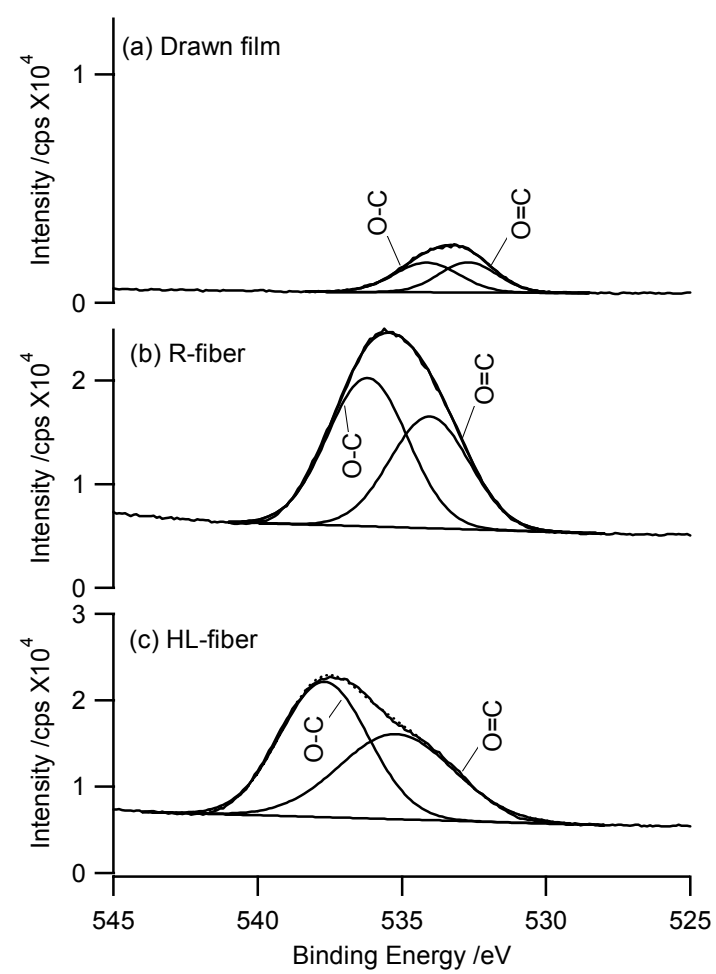

Fig. 5 XPS spectra of the $\mathrm{O}_{1 \mathrm{~s}}$ peak region at $535 \mathrm{eV}$ deconvoluted into surface functional group contributions for (a) drawn film, (b) R-fiber and (c) HL-fiber. 
Table 5-1 Composition of the total area of the $C_{1 s}$ peak region of the PET samples.

\begin{tabular}{cccc}
\hline & \multicolumn{3}{c}{ Consist $/ \%$} \\
\cline { 2 - 4 } & Drawn film & R-fiber & HL-fiber \\
\hline$-\mathrm{C}_{6} \mathrm{H}_{4}-$ & 66 & 14 & 15 \\
$-\mathrm{O}-\mathrm{CH}_{2}-\mathrm{CH}_{2}-\mathrm{O}-$ & 18 & 62 & 15 \\
$-\mathrm{O}-\mathrm{CO}-$ & 16 & 24 & 70 \\
\hline
\end{tabular}

Table 5-2 Composition of the total area of the $\mathrm{O}_{1 \mathrm{~s}}$ peak region of the PET samples.

\begin{tabular}{cccc}
\hline & \multicolumn{3}{c}{ Consist $/ \%$} \\
\cline { 2 - 4 } & Drawn film & R-fiber & HL-fiber \\
\hline$-\mathrm{O}-\mathrm{CH}_{2}-\mathrm{CH}_{2}-\mathrm{O}-$ & 52 & 57 & 47 \\
$-\mathrm{O}-\mathrm{CO}-$ & 48 & 43 & 53 \\
\hline
\end{tabular}

3.3 表面張力および XPS による検討から推定され た表面分子モデル
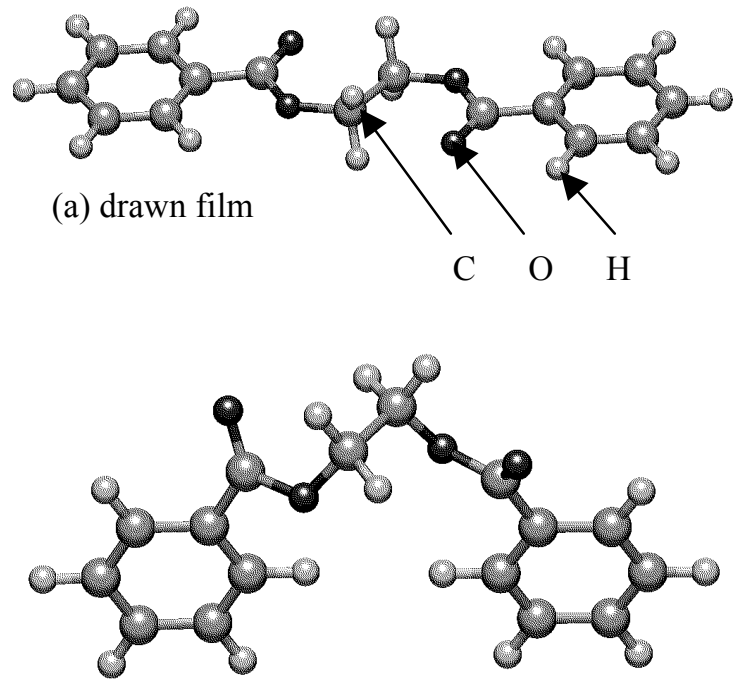

(b) R-fiber

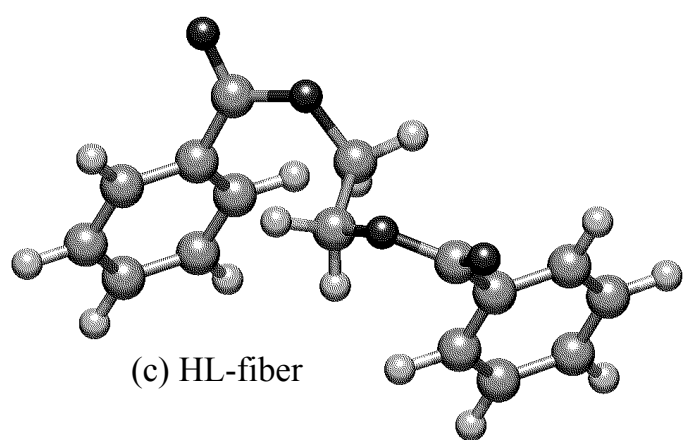

Fig. 6 The molecular models of PET film and fibers estimated by XPS and Surface tension studies.
表面張力および XPS による解析から, PET フィルムお よび 2 種の PET 繊維では, 最表面に特定の分子部位が偏在 している可能性が示唆された. 高分子鎖の異なる特定の分 子部位が最表面に偏在するには, 分子鎖の立体配座が異な らなければならない.これまでの検討から推定した PET フィルム及び 2 種の PET 繊維の表面分子モデルを Fig. 6 に, 幾何構造パラメータを Table 6 に示す. PET フィルムの場 合, ベンゼン環が表面に露出していること及び, エステル 結合が対称に配置している可能性を考慮して Fig. 6 (a)に示 す平面状の分子モデルが作成される. R-繊維の場合, エチ レングリコール鎖が表面に露出していることを考慮した 分子モデル, また, HL-繊維の場合, エステル結合部が表 面に露出していることを考慮した分子モデルがそれぞれ 作成される. PET 繊維のモデルは Fig. 6 (b), (c)に示すよう にエステル結合が Table 6 に示す角度でねじれている.

導出されたモデルから, フィルムの場合は平板状の構造 が積層されていると推定される。一方, 2 種の PET 繊維の 場合は, ベンゼン環が表面に対して垂直に配置し，なおか つ, 分子鎖がジグザクになっていると考えられる. R-繊維 は分子鎖の捻れが小さく, 極性のあるエチレングリコール 鎖が表面に露出していると考えられる. HL-繊維は分子鎖 の捻れが非常に大きく, エステル結合部分が最表面に露出 していると考えられる.

Table 6 Geometrical parameters for surface structure of PET film or fibers.

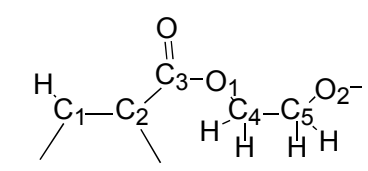

\begin{tabular}{lrrr} 
& \multicolumn{3}{c}{ Torsion $/^{\circ}$} \\
\cline { 2 - 4 } & Drawn film & R-fiber & HL-fiber \\
\hline $\mathrm{C}_{1}-\mathrm{C}_{2}-\mathrm{C}_{3}-\mathrm{O}_{1}$ & 0 & 140 & 130 \\
$\mathrm{C}_{2}-\mathrm{C}_{3}-\mathrm{O}_{1}-\mathrm{C}_{4}$ & 180 & 174 & 126 \\
$\mathrm{C}_{3}-\mathrm{O}_{1}-\mathrm{C}_{4}-\mathrm{C}_{5}$ & 0.0 & -77 & -77 \\
$\mathrm{O}_{1}-\mathrm{C}_{4}-\mathrm{C}_{5}-\mathrm{O}_{2}$ & -180 & -60 & -100 \\
\hline
\end{tabular}

\section{4. 結論}

以上, PET フィルム及び 2 種の PET 繊維の表面を比較し た. その結果, 平面状の PET フィルムと曲率を有する PET 繊維を直接比較する妥当性について課題を残すものの, PET フィルム・R-繊維・HL-䋊維の表面を接触角, 表面張 力及び XPS により解析した結果から, 各々の PET サンプ ルがそれぞれ全く異なる立体配座を有する表面分子構造 をとることの可能性が示された. 導き出した表面分子構造 からは, PET フィルムは, 表面に出現したベンゼン核のた めに疎水性を示す.一方, PET 繊維の場合には, 疎水性で あるが, 其の挙動は, PET フィルムとは異なる. また, エ 
チレングリコール鎖が最表面に露出している R-繊維より も, 最表面にエステル結合が露出している HL-䋊維の方が 表面の加水分解が容易に起こることも推定出来た. ゴム複 合材では, ゴム中から遊離するアミン類によるアミノリシ スや加水分解が原因とされるポリエステルコードやゴム 複合材の劣化がよく知られている[19,20]. 従って, HL-繊 維は R-繊維よりもアミノリシスや加水分解に注意すべき であろう.また, PET フィルムと比べて 2 種の PET 繊維は O/Cが極めて高い酸素が豊富な表面であるため酸化されに くく, 紫外線や $\mathrm{O}_{2}$ プラズマ処理等の物理的表面改質処理 法の効果が PET フィルムとは異なることが推定できる. 補 強用 PET 繊維の物理処理表面改質はいずれも費用対効果 で実用化されておらず，本研究で得られた表面分子モデ ル・立体配座は効果的な表面処理の研究に新しい知見を加 えると確信する. 更に, 研究を継続する予定である.

\section{文 献}

1. T. Takata, The proceeding of the $14^{\text {th }}$ Advanced technology Seminar sponsored by Elastomer workshop of Kurume Research park (November 14, 2003, in Kurume), p8 .

2. H-Celanese, Jpn. Tokkyo Koho, S63-528

3. J. Shimizu, K. Toriumi and K. Tamai, Sen'i Gakkaishi, 33, T-208 (1977).

4. J. Shimizu, N. Okui and T. Kikutani, Sen'i Gakkaishi, 37, P-135 (1981).

5. J. Shimizu, T. Kikutani, A. Takaku and N. Okui, Sen'i Gakkaishi, 37, T-135 (1981).
6. M. Matsui, Sen'i Gakkaishi, 38, P-508 (1982).

7. J. Shimizu, Sen'i Gakkaishi, 38, P-499 (1982).

8. J. Shimizu, Sen'i Kikai Gakkaishi, 38, P-243 (1985).

9. K. Kamide and T. Kuriki, Sen'i Kikai Gakkaishi, 38, P-268 (1985).

10. K. Fujimoto, K. Iohara, S. Ohwaki and Y. Murase, Sen'i Gakkaishi, 44, 53 (1988).

11. K. Fujimoto, K. Iohara, S. Ohwaki and Y. Murase, Sen'i Gakkaishi, 44, 171 (1988).

12. K. Fujimoto, K. Iohara, S. Ohwaki and Y. Murase, Sen'i Gakkaishi, 44, 477 (1988).

13. S. Ishizaki, K. Iohara and K. Fujimoto, Sen'i Gakkaishi, 45, P-234 (1989).

14. Y. Kitazaki and T. Hata, Nippon Setchaku Kyoukaishi, 8, 131 (1972).

15. B. J. Carroll, J. Colloid Interface Sci., 57, 488 (1976).

16. G. Gillberg and D. Kemp, J. Appl. Polym. Sci., 26, 2023 (1981).

17. D. Briggs, "Practical surface Analysis by Auger and $X$-ray photo electron Spectroscopy”, John wiley and Sons (1983), p287

18. C. Riccardi, R. Barni, E. Selli, G. Mazzone, M. R. Massafra, B. Marcandalli, G. Poletti, Appl. surf. sci., 211, 386 (2003).

19. Y. Shinada, and D. R. Hazelton, Rubber Chem. Technol., 51, 254 (1977).

20. K. Yabuki and S. Sawada, Sen'i Gakkaishi, 41, T-468 (1985). 